\title{
Aes World Heritage News: The Good, WAE the Bad and the Ugly
}

\author{
John Carman, Ironbridge International Institute for Cultural Heritage, School of \\ History and Cultures, College of Arts and Law, University of Birmingham, ERI Building, \\ Edgbaston, Birmingham, B15 2T, UK \\ E-mail: j.carman@bham.ac.uk
}

Jan Turek, Czech Institute of Egyptology, Charles University, Prague, Czech Republic E-mail: turekjan@hotmail.com

\section{Mosul: The Final Battle, the End of Destruction?}

During the final battle in the historic centre of Mosul, the second biggest city in Iraq, the Daesh militia blew up the Great Mosque of al-Nuri and its famous leaning minaret (the "al-Hadba"-"the hunchback") as jihadists battled to stop advancing pro-government Iraqi troops. The Iraqi army was within $50 \mathrm{~m}(160 \mathrm{ft})$ of the mosque when ISIS committed this final crime against the heritage of Mosul. The al-Nuri mosque dates back to 1172 and was Mosul's most famous Sunni mosque. It was named after Nur al-Din Mahmoud Zanki, leader of jihad against Christian crusaders. This was the same mosque where, in July 2014, Daesh leader Abu Bakr alBaghdadi declared the foundation of the new "Caliphate".

The damage to cultural heritage in Mosul and its surrounding area is enormous, but we have to bear in mind that it is not yet all over. Daesh is still controlling other smaller towns in Iraq, such as Tal Afar, part of ISIS's self-titled "Jazeera Province" which encompasses areas to the west of Mosul, near the Syrian border; Hawija, Riyad, Rashad, Zab and Abbasi in the "Kirkuk Province"; and al-Qaim, Rawa and Ana in the western province of Anbar.

The nightmare of fanatic iconoclasm and genocide is almost over in Mesopotamia; however, the example of recaptured Palmyra raises the question: How long may this last?

\section{A Call for Solidarity with Turkish Academics}

Following the arrest of 27 Turkish academics, and a criminal investigation into more than 1200 individuals across 90 Turkish universities in recent months, the Turkish Government has taken drastic steps towards restricting academic freedoms. Fortunately, all the arrested academics have since been released; however, if convicted, they could face up 15 years of impris- 
onment on counts of "propaganda against the government" and "insulting the Turkish government". A further 150 journalists are currently in prison, and currently 6 human rights activists are also held in custody.

For all of us who have experienced totalitarian regimes, this sounds familiar. Citizens are restricted in their freedom of speech and travel, and Turkey, a country with almost a hundred years of democratic development, is now drastically restricting human rights and democratic institutions. President Erdoğan is obviously attempting to drive his country into isolation from the union of democratic countries, but we cannot leave our colleagues in isolation and without support. They need to be supported in their struggle for democracy, as well as maintaining international academic contact. Please remember to send invitations to our Turkish colleagues and consider offering them fellowships and other kinds of cooperation. We can only hope that the roots of democracy in Turkey are stronger than it currently seems.

\section{New UNESCO World Heritage Sites}

On 12 July in Krakow (Poland) the World Heritage Committee inscribed 21 new sites on UNESCO's World Heritage List. It also extended or modified the boundaries of five sites already on the List. The new inscriptions bring to 1073 the total number of sites on the World Heritage List. We are pleased to announce that amongst the sites are also sites of archaeological and indigenous importance such as:

- Archaeological site of ancient Aphrodisias (Turkey).

- Caves and Ice Age Art in the Swabian Jura (Germany), where Modern humans first arrived in Europe 43,000 years ago.

- Kujataa Greenland: Norse and Inuit Farming at the Edge of the Ice Cap (Denmark).

- Valongo Wharf Archaeological Site (Brazil)

- ₹ Khomani Indigenous Cultural Landscape (South Africa).

- Temple Zone of Sambor Prei Kuk, Archaeological Site of Ancient Ishanapura (Cambodia).

However, there has been a controversial decision taken over Hebron/AlKhalil Old Town which includes the Cave of the Patriarchs. This is recognised by UNESCO as an endangered Palestinian heritage site. This is yet another culturally insensitive and unfair decision as the site is also important for Jews and Christians as the burial place of Abraham, Isaac, Jacob, Sarah, Rebecca and Leah, each of them a major figure from the Bible. It is a common and welcome practice that the nominations from more than 
one nation/country are being considered by the UNESCO World Heritage Committee. The same approach should have been taken in the case of Hebron/Al-Khalil as it is both Palestinian and Israeli. Such decisions certainly do not contribute towards the painful and lengthy process of Jewish-Palestinian reconciliation (Figure 1).

\section{This Issue}

We offer five substantive articles in this issue plus two other items. All five articles reflect this journal's concern with archaeology as a contemporary practice while recognising that the past as interpreted through materiality is the primary unit of analysis. Specific links between the past and the present are highlighted in three of the contributions, another demonstrates the value of studying the past to address current concerns, and another concerns the corporate culture of archaeology in a neoliberal environment. Geographically they cover four areas of the globe: Europe, Western Asia, South Asia and North America.

Manoj Kumar Singh offers an enlightening study of a continuing pottery-making culture in India that has its roots in the ancient past. As well as its inherent interest as a study of a particular cultural practice, the article raises interesting issues regarding cultural change and the concept of tradition persisting into the present. It also asserts the value of an ethnoarchaeological approach against recent charges that such approaches suffer from perpetuating old distinctions between "modern" and "premodern" societies and ignore issues of historical specificity and contingency (as suggested by Gosselain 2016). Arguments about archaeological method and theory are the meat and drink of the discipline and we are glad to contribute to them.

Xurxo Ayán offers a study of the uses to which a Spanish cave containing significant Palaeolithic art was put during periods of conflict in the 20th century. The article is one of the growing bodies of the literature that focuses upon the way archaeology contributes to the suppression and recovery of historical memory in Spain with all the trauma that implies. The paper raises issues central to WAC and this journal in terms of the relationship between archaeological material and practice on the one hand and political interests on the other. Memories in Spain of the 20th century are heavily overlain with emotion: work such as this emphasises to us all that we do not operate in an objective, detached realm but that we are intimately bound with others.

In Jordan-as in other territories across the world-the presence of major archaeological sites offers opportunities for tourism. However, as Abdelkader Ababneh makes clear, weak interpretation at such sites impedes 


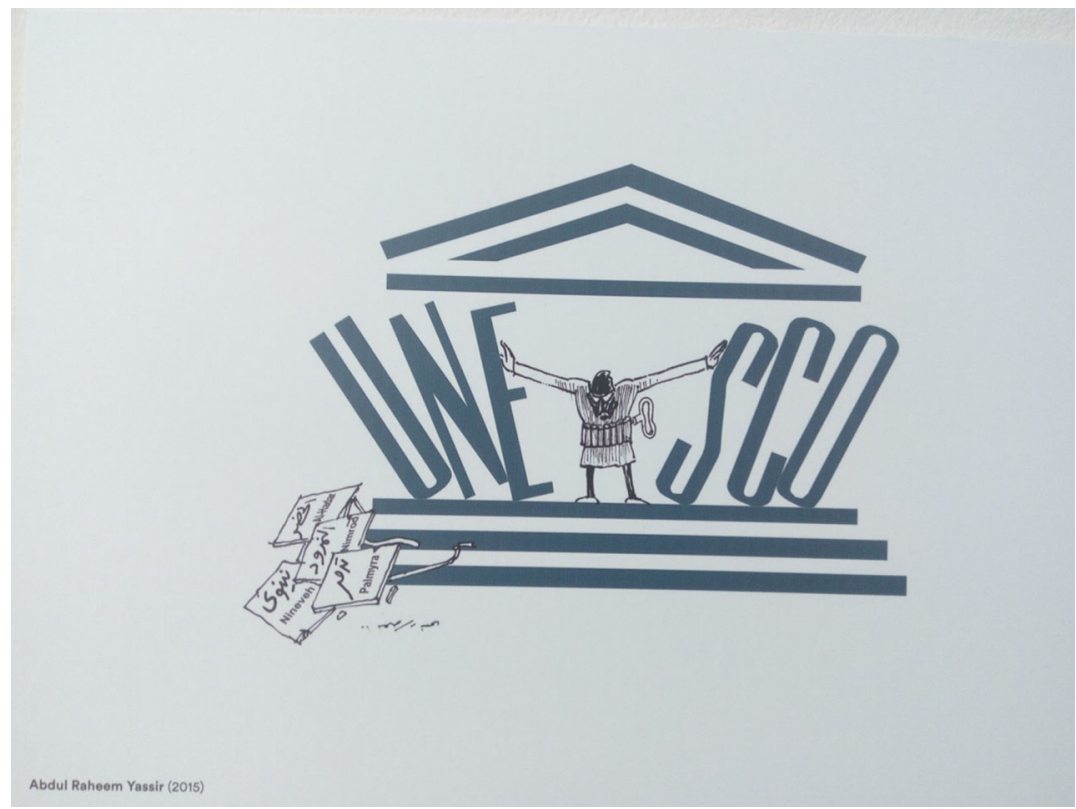

Figure 1. A UNESCO caricature by Abdul Raheem Yassir (courtesy of DOX Centre for Contemporary Art)

their effective management and attraction to visitors. The paper offers advice on how to progress these issues that should prove of value to others facing similar problems. More significantly, it analyses the mechanisms by which interpretations are constructed and compares these to generally accepted international standards. In this way, far from reducing the way we see archaeological sites to mere tourist sites, it provides an insight into one of the many roles for archaeology in the present globalised environment.

Similarly examining the role of archaeology in the present, Sean Cannaughton investigates the "corporate culture" of a CRM firm in Canada and how this relates to its relations with Indigenous cultures. Engagement with Indigenous communities is a core concern of both WAC and this journal, and so is also a concern with commercial archaeological practice in an era of neoliberal economics. Rarely, though, do these themes unite in a single contribution and this article addresses what changes to commercial archaeological practices need to be made to "decolonise" our work.

Tawseef Ahmad Mir returns to the south Asian subcontinent with a discussion of the manner in which ancient technologies may help us overcome problems we currently face. As global warming proceeds, the likelihood of major flooding incidents in various parts of the world 
increases. This contribution reveals the techniques used by the 3rd millennium BCE Harappan culture to mitigate the regular floods that affected its urban centres and discusses how modern cities can adopt them to deal with similar events. Closing the circle between past and present, it indicates a potential value for our work as archaeologists in dealing with a major threat to us all.

\section{WAC8 Resolutions}

Following the 8th World Archaeological Congress on Kyoto last year, we promised to publish the resolutions passed by that Congress and we are sorry it has taken a while to be able to that: you will see from their inclusion here that passing resolutions at a meeting is not the end of the story! Some need revision following discussion and amendment in plenary sessions and others may be subject to further changes as a result of technical issues related to WAC rules. This is particularly the case with Resolution 13 relating to contentions in Palestine. The resolutions nonetheless serve to demonstrate and emphasise WAC's ongoing commitments to engagement with political and human rights issues globally, and also to the complex nature of these issues which at once unite the archaeological community but can also divide us on issues of specific interpretation. We publish the resolutions without commentary.

\section{“No Comment" on Commentary}

As readers will know, we do not usually publish letters or engage in debates about our published material: while a very appropriate thing for academic journals to do, we choose to leave that to others. Just this once, however, we are publishing in this issue some items that represent exactly this kind of material. The issue in each is archaeologists' relations to Indigenous peoples and so highly relevant to us. We publish these also without further comment and do not invite further responses from our readers.

This may seem a contradictory approach to our general claim to wish to encourage debate amongst archaeologists and others. We do, however, confirm our desire to encourage debate. The current unfortunate trend in global communication is excessively to use brief statements and tweets rather than maintaining dialogue and critical discussion. We definitely do not want to go this way. For us, debate takes the form of longer pieces that go through the formal review process and so will enhance the standing of the journal, those who write for it and ultimately archaeology as a global discipline. We of course recognise what this means in terms of the respon- 
sibility it places upon ourselves, our Editorial Board and our reviewers to ensure the quality of our content. It also places on all of us a clear responsibility to respect others' different views on that content and the different kinds of contexts that archaeologists across the globe experience. Nobody said that these responsibilities would be easy to carry! And we rely very heavily on those who work with us to achieve and maintain the standards we aspire to.

In this spirit, we offer the following as a reminder to prospective authors:

We seek offers of papers of general archaeological concern from any area of the world that will inform archaeological practice, theory or understanding more widely and can especially challenge local and global power geometries. As part of our mission and distinctiveness, we recognise the especial importance of non-Western epistemologies and intellectual traditions and are keen to represent these in our pages. We are also keen to encourage younger colleagues to contribute to debates at the global level in the belief that they have new and distinctive perceptions of archaeology and its place in the world. We look forward to seeing your offers of contributions.

\section{Reference}

Gosselain, OP

2016. To hell with ethnoarchaeology!. Archaeological Dialogues 23(2):215-228. 